\title{
Spatial interpolation of monthly precipitation in selangor, Malaysia-Comparison and evaluation of methods
}

\author{
Nurul Nadiah Mohd FirdausHum ${ }^{1,}{ }^{*}$, Suhaimi Abdul -Talib ${ }^{2}$ \\ ${ }^{1}$ Faculty of Applied Sciences, Universiti Teknologi MARA, Malaysia \\ ${ }^{2}$ Faculty of Civil Engineering, Universiti Teknologi MARA, Malaysia
}

\author{
Index Terms \\ Precipitation \\ Interpolation \\ Cross-Validation \\ Kriging \\ IDW
}

Received: 7 November 2015

Accepted: 23 January 2016

Published: 22 February 2016

\begin{abstract}
There are many spatial interpolations schemes, but none of them can perform best in all cases. Hence, this study aims to find an optimal interpolation scheme for precipitation in Selangor and Langat basin of which are the two major basins in Selangor. In order to obtain spatially distributed precipitation data, 21 measured rain gauges points are interpolated. Five interpolation methods have been tested after exploring data and cross-validation was used as the criterion to evaluate the accuracy of the various methods. The best method was obtained by the kriging method while the inverse distance weighting (IDW) perform worst.
\end{abstract}

(C) 2016 The Author(s). Published by TAF Publishing.

\section{INTRODUCTION}

Hydrology and water quality applications in catchment areas no doubt require data on the most important parameter which is the precipitation. Since these data are often collected using the rain gauge, they are then considered as point data. However, the use of single rain gauges as precipitation inputs carries great uncertainties regarding runoff estimation [1]. This presents a great problem for the prediction of discharge, groundwater level and soil moisture, especially if the rain gauge is located outside of the catchment [2]. As result, some applications such as precipitationmapping on erosions [3],[4],[5],[6],[7]

\footnotetext{
* Corresponding author: Nurul Nadiah Mohd FirdausHum E-mail: nadiah0978@gmail.com
}

and hydrological modelling [8], [9],[10],[11],[12],[13],[14] require precipitation data that are spatially continuous. The quality of such result is thus determined by the quality of the continuous spatial precipitation [15], [16], [9], [17], [14].

Spatial interpolation can be used to estimate precipitation variables at other locations. Although there are several methods to perform this, it can be a challenging task to determine which of the methods produce the results closest to the actual conditions. Each methods advantage and their disadvantages hence depend strongly on the characteristics of the data set used in order to define their suitability. Thus, criteria must be fund to decide whether the method chosen is suited for the point data set. Besides, it is also important to define the aims of the interpolation as different aims can represent different 
criteria for the evaluation of the interpolation method used. The most frequently used deterministic methods in spatial interpolation for precipitation are the Thiessen polygon and Inverse Distance Weighting (IDW) while the geostatistical method constitutes a discipline involving mathematics and earth sciences. [18] compared Inverse Distance Weighting, the Thiessen polygon and kriging in interpolating precipitation data from a network of thirteen rain gages on Norfolk Island. They recommended the use of IDW for interpolations for spatially dense networks. [19] used cross validation to evaluate four forms of kriging and three simple alternatives for spatial interpolation of climatic data.

They found that IDW had a smaller error of estimates than Ordinary Kriging (ORK) and Universal Kriging (UNK) in interpolating monthly precipitation in the Canadian boreal forest. [20] studied the variability of spatial and temporal precipitation in the south Ecuadorian Andes using the Thiessen polygon and kriging. Their study suggested that spatial interpolation with kriging gives better a result than Thiessen polygon, and the accuracy of both methods improves when external trends are incorporated. [21] analysed the spatial distribution of precipitation in the Indian Himalayas using both deterministic and geostatistical methods. They reported that UNK was the most suitable method, followed by ORK and IDW.

Although comparisons of interpolation Methods for precipitation in numerous areas of the world has been studied,[22],[23],[24],[25],[26],[27],[28],[29][30],[31],[32] [33], [34] review of the literature reveals that no interpolation study of climatic variables has been applied to the study area. However, there is a single attempt to introduce a method for estimating mean monthly precipitation in the Langat River Basin, Selangor by analyzing its precipitation trend [35].

In this study five GIS-based spatial interpolation methods were compared to determine their suitability for estimating mean monthly precipitation, from data recorded at nearly 21 rain gauges in Selangor. This study is then constructed in two parts: the first consists of the presentation of the precipitation network in Selangor, the available data and the different methods used to spatially interpolate the precipitation of the area. While the second part presents the methodological of the analysis and the results obtained from the evaluation method. In this part, cross-validation method isused to assess which method gives the best interpolation.

\section{MATERIALS AND METHOD}

\section{A. Study Area}

The Selangor and Langat River basin in the Selangor state is used as the case study basin. The total area of the study basin is around $2514.13 \mathrm{sq}$. $\mathrm{km}$. and the climate is Tropical with hot, dry season and wet monsoon season.The basin is divided into 34 subcatchment areas (20 in Selangor catchment and 14 in Langat catchment), each of which is a source of surface runoff as well as an independent groundwater aquifer.

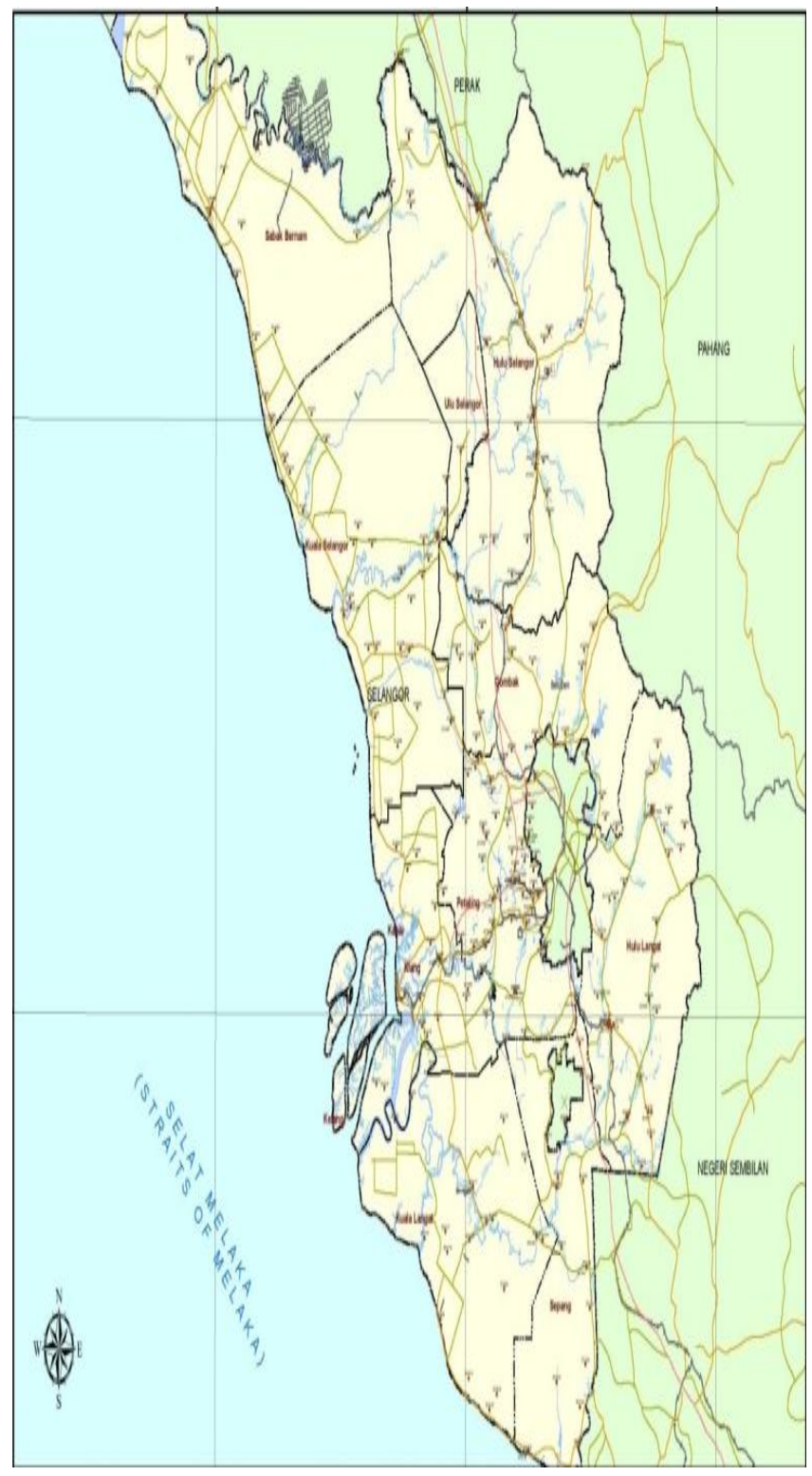

Fig.1. Schematic Localityofthe Basins inSelangor 


\section{Selangor catchment}

Sungai Selangor basin which is located in the state of Selangor is approximately $70 \mathrm{~km}$ long and $30 \mathrm{~km}$ wide that stretches from Bukit Fraser on the northeast to the Straits of Malacca in the west with a catchment area of 1820 sq. $\mathrm{km}$. Among the main tributaries in the basin area are $\mathrm{Sg}$ Batang Kali, Sg Serendah, Sg Kuang, Sg Ranching, Sg Buloh, Sg Kerling and Sg Garing. The flow of the Sungai Selangor in general is in the south west direction before ending into the Straits of Malacca via the town of Kuala Selangor. Alluvial soils accounted $55 \%$ of the area which mainly are in the coastal plains and riverine areas, although part of this area especially the coastal peat area have been drained for paddy cultivation while some hilly areas are cultivated for oil palm and rubber plantation. Selangor basin experienced high temperature and humidity with a relatively small amount of seasonal variations besides subjected to two monsoonal periods which are the Northeast Monsoon (October till January) and the Southwest Monsoon (May to September). Average precipitation is in the range of $2000 \mathrm{~mm}$ to $3500 \mathrm{~mm}$ with the largest peak during the Northeast Monsoon.

\section{Langat Catchment}

The Langat basin is located at the southern part of Klang Valley which is the most urbanized river basin in Malaysia.
It is believed that the Langat basin is currently experiencing "spill over" effects due to excessive development in the Klang Valley. Hydro meteorologically, the Langat basin is affected by two types of monsoon, i.e. the northeast (November-March) and the southwest (May-September) monsoons. Average annual precipitation is about $2400 \mathrm{~mm}$. The wettest months are April and November with average monthly precipitation exceeding $250 \mathrm{~mm}$, while the driest month is June with average monthly precipitation not exceeding $100 \mathrm{~mm}$. Topographically, the Langat basin can be divided into three distinct areas with reference to the Langat River: the mountainous area in the upstream, undulating land in the centre and flat flood plain in the downstream. The basin has a rich density of landforms; surface features and land cover [35].

\section{B. Data Collection}

The data used in this study comprise continuous records of mean monthly precipitation for the period (1970-2010) in 21stations scattered throughout the study area (Fig. 2). These data have been originally provided by the Department of Irrigation and Drainage Malaysia for all precipitation gauges in the study area.

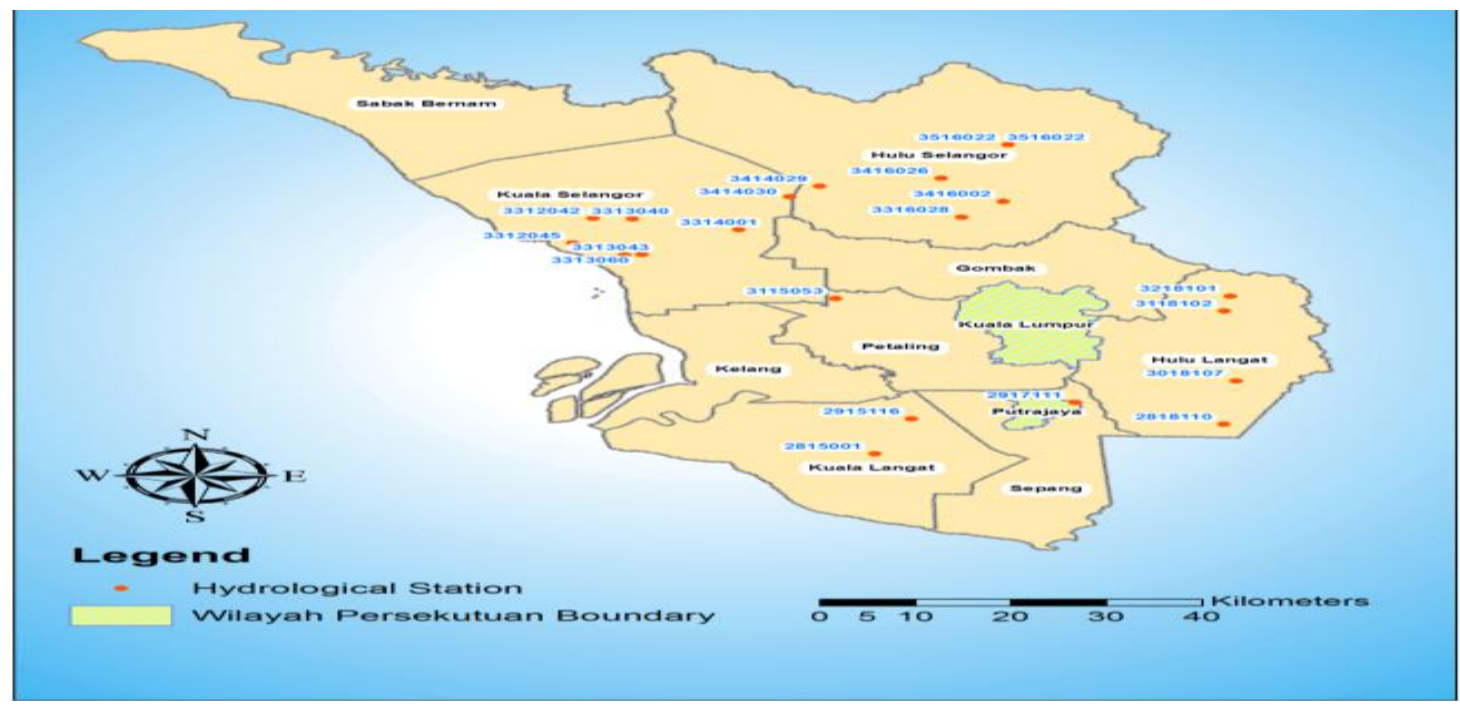

Fig. 2. Location of the 21 rain gauges stations used in the study

\section{INTERPOLATION METHOD}

The interpolation methods used in this study were performed by ESRI ArcGIS® Geostatistical Analyst 10.2. Geostatistical Analyst is an extension to the ArcGIS Desktop that provides a powerful suite of tools for spatial data exploration and surface generation using sophisticated statistical methods. Geostatistical Analyst provides two groups of interpolation techniques: deterministic and geostatistical. All methods rely on the similarity of nearby sample points to create the surface. Deterministic techniques use mathematical functions for 
interpolation. Geostatistics relies on both statistical and mathematicalmethods, which can be used to create surfaces and assessthe uncertainty of the predictions. This section briefly introduces the different interpolation methods used in this study, detailed descriptions of these methods are reported elsewhere [36],[37],[38],[39].

\section{Deterministic Methods}

Deterministic interpolation methods create surfaces from measured points, based on either the extent of similarity like Inverse Distance Weighted or the degree of smoothing such as Radial Basis Functions. Deterministic interpolation methods can be divided into two groups: global and local. Global methods calculate predictions using the entire dataset. Local methods calculate predictions from the measured points within neighbourhoods, which are smaller spatial areas within the larger study area. Geostatistical Analyst provides the Global Polynomial as a global interpolator and the Inverse Distance Weighted, Local Polynomial, and Radial Basis Functions as local interpolators. Deterministic interpolation techniques may be exact or inexact interpolators. Exact interpolators such as Inverse Distance Weighted Interpolation and Radial Basis Functions generate a surface that passes through the control points. In contrast, inexact interpolators such as Global and Local Polynomial predict a value at the point location that differs from its known value.

\section{Inverse Distance Weighted (IDW) Interpolation}

IDW is the workhorse of spatial interpolation, the method that is most often used by GIS analysts. It employs the Tobler's First Law of Geography by estimating unknown measurements as weighted averages over the known measurements at nearby points, giving the greatest weight to the nearest points [40]. The general equation for IDW method is shown in equation (1):

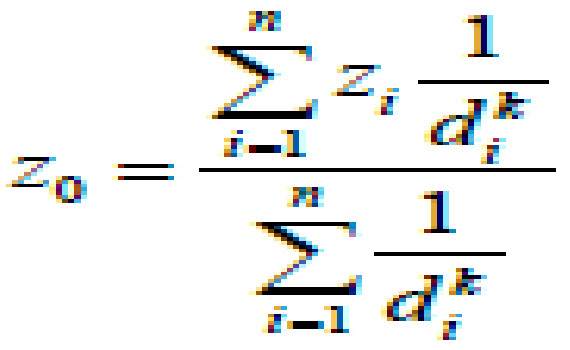

Where $\mathrm{Z0}$ is the estimated value at point 0 , Ziis the Zvalue at known point $\mathrm{i}$, diis the distance between point iand point $0, \mathrm{n}$ is the number of known points used in estimation, and $\mathrm{k}$ is the specified power which controls the degree of local influence [38].

\section{Global Polynomial (GP) Interpolation}

GP interpolation simply uses multiple regression methods on all of the data. A response or trend surface is fitted to the $\mathrm{x}$-and $\mathrm{y}$-coordinates, which are the covariates. A first-order Global Polynomial (linear) fits a single plane through the data as shown in equation (2):

$\mathrm{Z}(\mathrm{Xi}, \mathrm{Yi})=\beta 0+\beta 1 \mathrm{Xi}+\beta 2 \mathrm{Yi}+\varepsilon(\mathrm{Xi}, \mathrm{Yi})$

Where $\mathrm{Z}(\mathrm{Xi}, \mathrm{Yi})$ is the datum at location (Xi, Yi), $\beta$ iare parameters,and $\varepsilon(\mathrm{Xi}, \mathrm{Yi})$ is a random error. A secondorder Global Polynomial (quadratic) fits a surface with a bend in it, allowing surfaces representing valleys; a thirdorder Global Polynomial (cubic) allows for two bends; and so forth, up to a 10 are allowed in Geostatistical Analyst [36].

\section{E. Local Polynomial (LP) Interpolation}

As with global polynomials a least square polynomial fit to the data is applied, with options for Order 1,2 or 3 equations.However, instead of fitting the polynomial to the entiredataset it is fitted to a local subset defined by a window. Thesize of this window needs to be large enough for a reasonablenumber of data points to be included in the process. Onefurther adjustment is made to this procedure - a measure ofdistance-based weighting is included, so the least squaresmodel is in fact a weighted least squares fit. The weights arecomputed using a power function of distance as a fraction ofthe window size. The simplest case is where the movingwindow is a circle with radius $\mathrm{R}$. If the distance between gridpoint ( $\mathrm{Xi}, \mathrm{Yi}$ ) and a data point $(\mathrm{x}, \mathrm{y})$ within the circle is denoteddi, then the weight wiis given by equation (3) and the leastsquares procedure then involves minimizing the expression given by equation (4) :

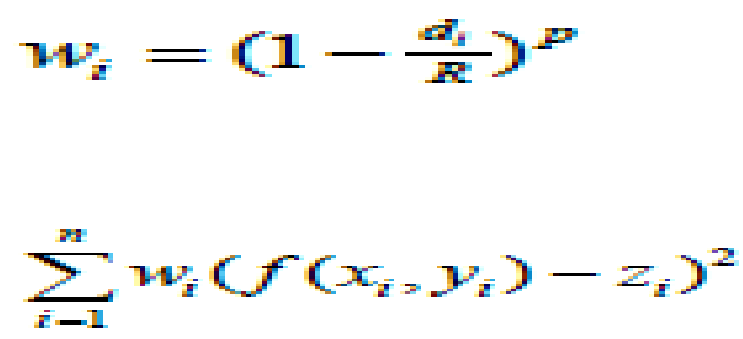

Where $\mathrm{p}$ is a user definable power and if $\mathrm{p}=0$ all the weights are 1. 


\section{F. Geo Statistical Methods}

Geo statistical interpolation methods create surfaces incorporating the statistical properties of the measured data. These techniques produce not only prediction surfaces but also error or uncertainty surfaces, giving the analyst an indication of how good the predictions are. Many methods are associated with geostatistics, but all are in the Kriging family. Kriging assumes that the spatial variation of an attribute is neither totally random (stochastic) nor deterministic. Instead, the spatial variation may consist of three components: a spatially correlated component, variation representation of the regionalized variable in the form of a "drift" or structure that represents a trend; and a random error term. The interpretation of these components has led to development of different Kriging methods for spatial interpolation. In this study, Ordinary and Universal Kriging was used.

\section{G. Ordinary Kriging}

Assuming the absence of a drift, Ordinary Kriging (OK) focuses on the spatially correlated component and uses the fitted semivariogram, a diagram relating the semivariance to the distance between sample points used in Kriging, directly for interpolation. The estimator of ordinary Kriging is given by equation (6):

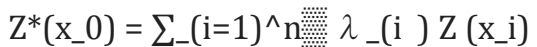

Where $\mathrm{Z}^{*}(\mathrm{x} 0)$ is the estimate value at $\mathrm{x} 0, \mathrm{Z}(\mathrm{xi})$ is the measure value at the xiand $\lambda$ iis the weight assigned for the residual of $\mathrm{Z}(\mathrm{xi})$ [41].

\section{H. Universal Kriging}

Universal Kriging (UK) assumes that the spatial variation in $\mathrm{z}$ values has a drift or a trend in addition to the spatial correlation between the sample points. By definition of the drift component, the expected value $\mathrm{m}(\mathrm{x})$ of $\mathrm{z}(\mathrm{x})$ at point $\mathrm{z}$ is given by equation (7) and the estimator of universal Kriging is given by equation (8) [41]:

$$
\begin{aligned}
& \mathrm{E}[\mathrm{Z}(\chi)]=\mathrm{m}(x)
\end{aligned}
$$

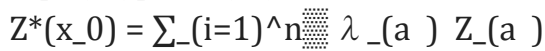

Where nthe number of is available sampling data, $\mathrm{Z}^{*}(\mathrm{x} 0)$ is the estimate value, Zais the measured value at sampling point $\mathrm{a}(\mathrm{a}=1, \ldots, \mathrm{n})$, and $\lambda$ ais the weighting coefficient, which is calculated with unbiased and minimum error variance.

\section{Cross-Validation}

Cross-Validation was used to evaluate the performance of each interpolation method. It is one of the most commonly used statistical techniques for comparing interpolation methods. Cross-Validation compares the interpolation methods by repeating the following procedure for each interpolation method to be compared [44] (1) Remove a known point from the data set, (2) Use the remaining points to estimate the value at the point previously removed, and (3) Calculate the predicted error of the estimation by comparing the estimated with the known value. After completing the procedure for each known point, two common diagnostic statistics, Root Mean Square Error (RMSE) and the standardized RMSE, are calculated to assess the accuracy of the interpolation method as shown in equations (9) and (10):

$\mathrm{RMSE}=\sqrt{\frac{1}{n} \sum_{i=1}^{n}(Z i-Z)^{2}}$

Standardized RMSE $=$ RMSE $/ \mathrm{S}$

Where Ziand Zare the measured and the estimated value at the sampling point $i(i=1,2, \ldots n) ; n$ is the number of values used for the estimation; and $\mathrm{S}$ is the standard error. The RMSE statistic is available for all exact local methods, but the Standardized RMSE is only available for Kriging because the variance is required for computation. A better interpolation method should yield a smaller RMSE and a better Kriging method should yield a smaller RMSE and aStandardized RMSE closer to 1 [38].

\section{RESULTS AND DISCUSSION}

Mean Monthly Precipitation for two selected months (Jun and October) as representatives of the two monsoon seasons (South West Monsoon and South East Monsoon) in Selangor was interpolated in turn using five GIS based interpolation techniques (IDW, LP, GP, OK, UK). Fig. 3 shows samples of interpolated surfaces using different methods. RMSE (for the six methods) and Standardized RMSE (for only OK and UK) were then calculated using Cross-Validation as shown in Fig. 4. The minimal RMSE are obtained by OK and UK, which have almost the same RMSE and Standardized RMSE for all months. Thus this method is the optimal method for interpolating mean monthly precipitation in the study area. Similar results were obtained from [42], [43], [21], [44] and [45] where their studies found that interpolation using $\mathrm{OK}$ and UK were the optimal method in addressing the precipitation of their studied area. 

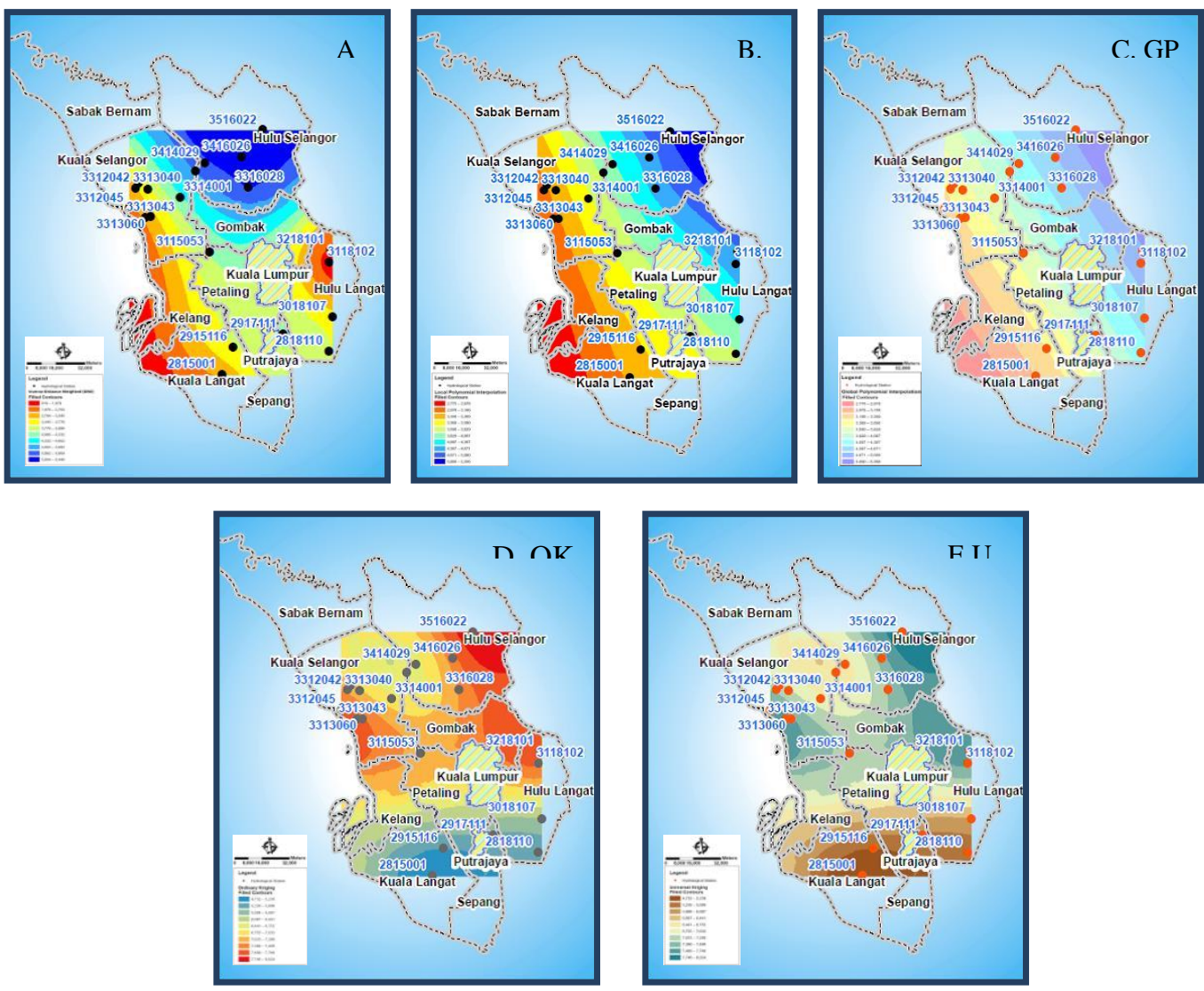

Fig. 3. Sample of the mean monthly precipitation (mm) of $1970-2010$ in Selangor for the five interpolation methods used

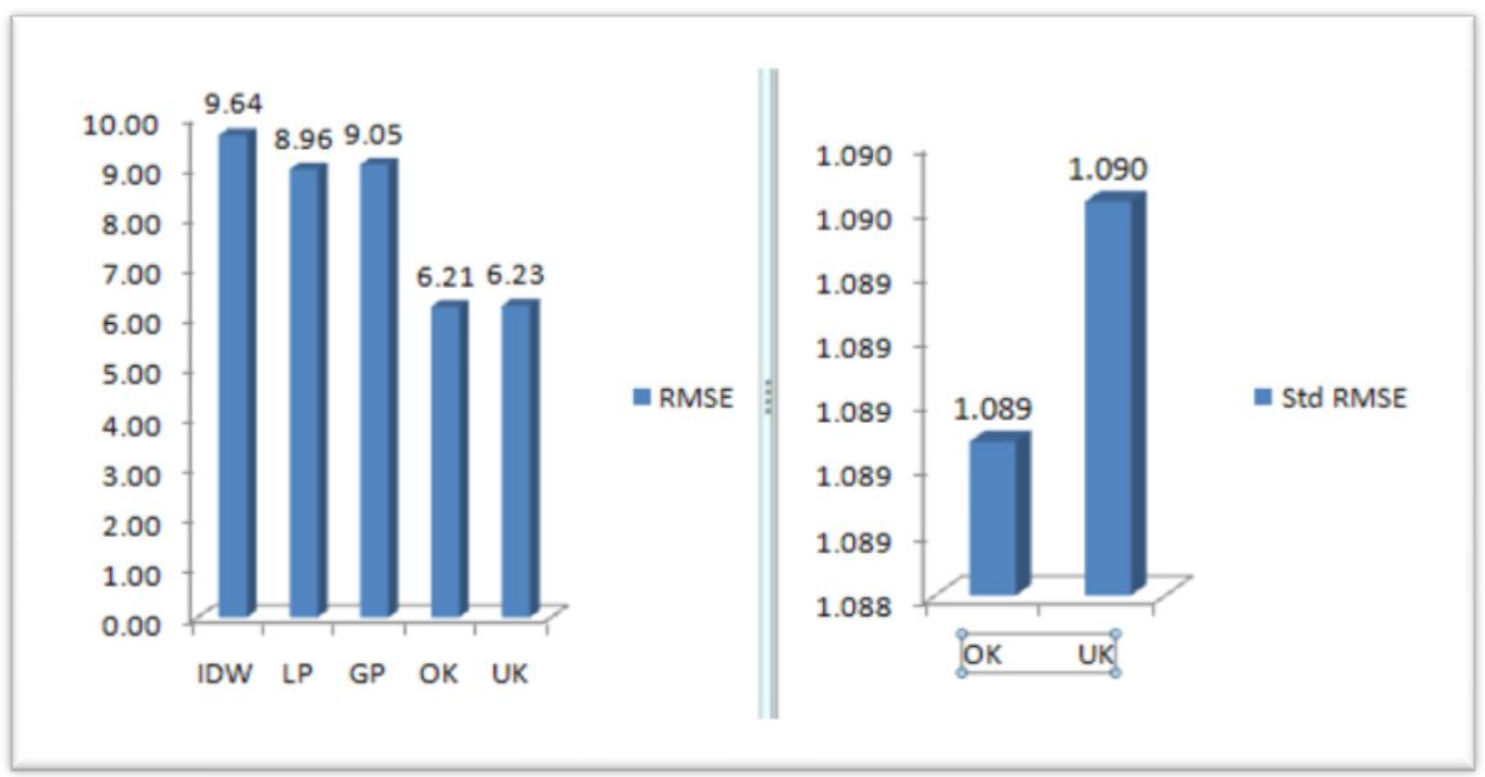

Fig. 4. Root mean square error (rmse) for the five interpolated methods and standardized rmse 


\section{CONCLUSION}

Ordinary Kriging and Universal Kriging are themost optimal methods for interpolating mean monthly precipitation in Selangor. This conclusion is based on available precipitation data recorded 21 rain gauges stations representing two main catchments; Langat and Selangor during the period (1970-2010), which were in turn interpolated using five GIS-based interpolation methods. Cross-Validation was used to compare the various interpolation methods. Diagnostic Statistic indicated that Ordinary and Universal Kriging had the smallest RMSE and thus they are considered the optimal methods for interpolating precipitation in Selangor.

\section{ACKNOWLEDGEMENT}

This research was supported by the International Foundation of Sciences (IFS) grant (W/5238-1), the Department of Irrigation and Drainage Malaysia for the precipitation data and Universiti Teknologi MARA Malaysia.

\section{REFERENCES}

[1] I. Chaubey, C. T. Haan, S. Grunwald and J. M. Salisbury, "Uncertainty in the model parameters due to spatial variability of rainfall," Journal of Hydrology, vol. 220, no. 1 , pp. 48-61, 1999 . DOI: 10.1016/S00221694(99)00063-3

[2] J. M. Schuurmans and M. F. P. Bierkens, "Effect of spatial distribution of daily rainfall on interior catchment response of a distributed hydrological model," Hydrology and Earth System Sciences Discussions, vol.11, no. 2, pp. 677-693, 2007. DOI: 10.5194/hess-11-677-2007

[3] G. Aronica and V. Ferro, "Rainfall erosivity over the Calabrian region," Hydrological Sciences Journal, vol. 42, no. 1, pp. 35-48, 1997. DOI: $10.1080 / 02626669709492004$

[4] P. Goovaerts, "Using elevation to aid the geostatistical mapping of rainfall erosivity," Catena, vol. 34, no. 3, pp. 227-242, 1999. DOI: 10.1016/S0341-8162(98)00116-7

[5] N. Hoyos, P. R. Waylen and Á. Jaramillo, "Seasonal and spatial patterns of erosivity in a tropical watershed of the Colombian Andes," Journal of Hydrology, vol. 314, no. 1, pp. 177-191, 2005. DOI:

10.1016/j.jhydrol.2005.03.014

[6] J. Nyssen, H. Vandenreyken, J. Poesen, J. Moeyersons, J. Deckers, M. Haile and G. Govers, "Rainfall erosivity and variability in the Northern Ethiopian Highlands," Journal of Hydrology, vol. 311, no. 1, pp. 172-187, 2005.
DOI: $10.1016 / j . j h y d r o l .2004 .12 .016$

[7] M. Angulo-Martínez and S. Beguería, "Estimating rainfall erosivity from daily precipitation records: A comparison among methods using data from the Ebro Basin (NE Spain)," Journal of Hydrology, vol. 379, no. 1, pp. 111-121, 2009. DOI: 10.1016/j.jhydrol.2009.09.051

[8] K. H. Syed, D. C. Goodrich, D. E. Myers and S. Sorooshian, "Spatial characteristics of thunderstorm rainfall fields and their relation to runoff," Journal of Hydrology, vol. 271, no. 1, pp. 1-21, 2003. DOI: 10.1016/S0022-1694(02)00311-6

[9] M. Kobold, "Precipitation forecasts and their uncertainty as input into hydrological models," Hydrology and Earth System Sciences Discussions, vol. 9, no. 4, pp. 322-332, 2005. DOI: 10.5194/hess-9-322-2005

[10] S. Gabellani, G. Boni, L. Ferraris, J. Von Hardenberg and A. Provenzale, "Propagation of uncertainty from rainfall to run off: A case study with a stochastic rainfall generator," Advances in Water Resources, vol. 30, no. 10, pp. 2061-2071, 2007. DOI: 10.1016/j.advwatres.2006.11.015

[11] S. J. Cole and R. J. Moore, "Hydrological modelling using raingauge-and radar-based estimators of areal rainfall," Journal of Hydrology, vol. 358, no. 3, pp. 159181, 2008. DOI:

10.1016/j.jhydrol.2008.05.025

[12] B. Collischonn, W. Collischonn and C. E. M. Tucci, "Daily hydrological modeling in the Amazon basin using TRMM rainfall estimates," Journal of Hydrology, vol. 360, no. 1, pp. 207-216, 2008. DOI: 10.1016/j.jhydrol.2008.07.032

[13] D. Ruelland, S. Ardoin-Bardin, G. Billen and E. Servat, "Sensitivity of a lumped and semi-distributed hydrological model to several methods of rainfall interpolation on a large basin in West Africa," Journal of Hydrology, vol. 361, no. 1, pp. 96-117, 2008.

DOI:10.1016/j.jhydrol.2008.07.049

[14] L. Moulin, E. Gaume and C. Obled, "Uncertainties on mean areal precipitation: assessment and impact on streamflow simulations." Hydrology and Earth System Sciences, vol. 13, no. 2, pp. 99-114, 2009. D0I: 10.5194/hess-13-99-2009

[15] V. P. Singh, "Effect of spatial and temporal variability in rainfall and watershed characteristics on stream flow hydrograph," Hydrological Processes, vol. 11, no.

12, pp. 1649-1669, 1997. DOI: 10.1002/(SICI)10991085(1997015)

[16] V. Andréassian, C. Perrin, C. Michel, I. Usart-Sanchez and J. Lavabre, "Impact of imperfect rainfall 
knowledge on the efficiency and the parameters of watershed models," Journal of Hydrology, vol. 250, no. 1, pp. 206-223, 2001. DOI: 10.1016/S0022-1694(01)00437-1

[17] R. Leander, T. A. Buishand, B. J. van den Hurk and M. J. de Wit, "Estimated changes in flood quantiles of the river Meuse from resampling of regional climate model output." Journal of Hydrology, vol. 351, no. 3, pp. 331-343, 2008. DOI:

10.1016/j.jhydrol.2007.12.020

[18] K. N. Dirks, J. E. Hay, C. D. Stow and D. Harris, "Highresolution studies of rainfall on Norfolk Island: Part II: Interpolation of rainfall data." Journal of Hydrology, vol. 208, no. 3, pp. 187-193, 1998. DOI: 10.1016/S0022-1694(98)00155-3

[19] I. A. Nalder and R. W. Wein, "Spatial interpolation of climatic normals: test of a new method in the Canadian boreal forest." Agricultural and forest meteorology, vol. 92 , no. 4, pp. 211-225, 1998. DOI: 10.1016/S0168-1923(98)00102-6

[20] W. Buytaert, R. Celleri, P. Willems, B. De Bievre and G. Wyseure, "Spatial and temporal rainfall variability in mountainous areas: A case study from the south Ecuadorian Andes." Journal of hydrology, vol. 329, no. 3, pp. 413-421, 2006. DOI: 10.1016/j.jhydrol.2006.02.031

[21] A. Basistha, D. S. Arya and N. K. Goel, "Spatial distribution of rainfall in Indian Himalayas-a case study of Uttarakhand region." Water Resources Management, vol. 22, no. 10, pp. 1325-1346, 2008. DOI: $10.1007 / \mathrm{s} 11269-007-9228-2$

[22] M. R. Holdaway, "Spatial modeling and interpolation of monthly temperature using kriging." Climate Research, vol. 6, no. 3, pp. 215-225, 1996. DOI: $10.3354 / \mathrm{cr} 006215$

[23] R. Dodson and D. Marks, "Daily air temperature interpolated at high spatial resolution over a large mountainous region." Climate Research, vol. 8, no. 1, pp. 1-20, 1997. DOI: $10.3354 / \mathrm{cr} 008001$

[24] P. E. Thornton, S. W. Running and M. A. White, "Generating surfaces of daily meteorological variables over large regions of complex terrain." Journal of Hydrology, vol. 19, no. 3, pp. 214-251, 1997. DOI: $10.1016 / S 0022-1694(96) 03128-9$

[25] Y. Xia, M. Winterhalter and P. Fabian, "A model to interpolate monthly mean climatological data at Bavarian forest climate stations." Theoretical and applied climatology, vol. 64, no. 1-2, pp. 27-38, 1999. DOI: $10.1007 / \mathrm{s} 007040050108$

[26] Y. Xia, P. Fabian, M. Winterhalter and M. Zhao, "Forest climatology: estimation and use of daily climatological data for Bavaria, Germany." Agricultural and Forest Meteorology, vol. 106, no. 2, pp. 87-103, 2001. DOI:

\section{$10.1016 / S 0168-1923(00) 00210-0$}

[27] D. Courault and P. Monestiez, "Spatial interpolation of air temperature according to atmospheric circulation patterns in southeast France." International Journal of Climatology, vol. 19, no. 4, pp. 365-378, 1999. DOI: 10.1002/(SICI)1097-0088(19990330)

[28] H. Hasenauer, K. Merganicova, R. Petritsch, S. A. Pietsch and P. E. Thornton, "Validating daily climate interpolations over complex terrain in Austria." Agricultural and Forest Meteorology, vol. 119, no. 1, pp. 87-107, 2003. DOI: 10.1016/S0168-1923(03)00114-X

[29] A. Berne, G. Delrieu, J. D. Creutin and C. Obled, "Temporal and spatial resolution of rainfall measurements required for urban hydrology." Journal of Hydrology,vol. 299, no. 3, pp. 166-179, 2004. DOI: $10.1016 / S 0022-1694(04) 00363-4$

[30] D. C. Garen and D. Marks, "Spatially distributed energy balance snowmelt modelling in a mountainous river basin: Estimation of meteorological inputs and verification of model results," Journal of Hydrology, vol. 315, no. 1, pp. 126-153, 2005. DOI: 10.1016/j.jhydrol.2005.03.026

[31] K. Stahl, R. D. Moore, J. A. Floyer, M. G. Asplin and I. G. McKendry, "Comparison of approaches for spatial interpolation of daily air temperature in a large region with complex topography and highly variable station density." Agricultural and Forest Meteorology, vol. 139, no. 3, pp. 224-236, 2006. DOI: 10.1016/j.agrformet.2006.07.004

[32] F. Attorre, M. Alfo, M. De Sanctis, F. Francesconi and F. Bruno, "Comparison of interpolation methods for mapping climatic and bioclimatic variables at regional scale," International Journal of Climatology, vol. 27, no. 13, pp. 1825-1843, 2007. DOI: $10.1002 /$ joc. 1495

[33] M. Keblouti, L. Ouerdachi and H. Boutaghane, "Spatial interpolation of annual precipitation in AnnabaAlgeria-comparison and evaluation of methods." Energy Procedia, vol. 18, pp. 468-475, 2012. DOI: http://dx.doi.org/10.1016/j.egypro.2012.05.058

[34] S. Wang, G. H. Huang, Q. G. Lin, Z. Li, H. Zhang and Y. R. Fan, "Comparison of interpolation methods for estimating spatial distribution of precipitation in Ontario, Canada," International Journal of Climatology, vol. 34, no. 14, pp. 3745-3751, 2014. DOI: $10.1002 /$ joc.3941

[35] N. Palizdan, Y. Falamarzi, Y. F. Huang, T. S. Lee and A. H. Ghazali, "Regional precipitation trend analysis at the Langat River Basin, Selangor, Malaysia." 
Theoretical and Applied Climatology, vol. 117, no. 34, pp. 589-606, 2014. DOI:

10.1007/s00704-013-1026-6

[36] K. Johnston, J. M. Ver Hoef, K. Krivoruchko and N. Lucas, Using ArcGIS Geostatistical Analyst. Redlands, CA: ESRI Press, 2001.

[37] J. Li and A. D. Heap, "A review of comparative studies of spatial interpolation methods in environmental sciences: Performance and impact factors," Ecological Informatics, vol. 6, no. 2-3, 2008.

[38] K. T. Chang, "Introduction to Geographic Information Systems," Boston, MA: McGraw-Hill, 2006. DOI: 10.1080/13658810600607857

[39] C. Lloyd, Spatial Data Analysis: An Introduction for GIS Users. New York, NY: Oxford University Press, 2010.

[40] P. A. Longley, M. F. Goodchild, D. J. Maguire and D. W. Rhind, "Geographic Information System and Science." London, UK: John Wiley \& Sons, Ltd, 2001.

[41] Y. Sun, S. Kang, F. Li and L. Zhang, "Comparison of interpolation methods for depth to groundwater and its temporal and spatial variations in the Minqin oasis of northwest China." Environmental Modelling \& Software, vol. 24, no. 10, pp. 1163-1170, 2009. DOI: $10.1016 /$ j.envsoft.2009.03.009

[42] D. Nusret and S. Dug, "Applying the inverse distance weighting and kriging methods of the spatial interpolation on the mapping the annual precipitation in Bosnia and Herzegovina," In International Congress on Environmental Modelling and Software Managing Resources of a Limited Planet, Sixth Biennial Meeting, Leipzig, Germany 2012.

[43] A. Ayansina and S. Ogunbo, "GIS approach in assessing seasonal rainfall variability in Guinea Savanna part of Nigeria." in Proc. Seventh Int. FIG Regional Conference, Vietnam, 2009, pp. 19-22.

[44] P. M. Atkinson and C. D. Lloyd, "Mapping precipitation in Switzerland with ordinary and indicator kriging. Special issue: Spatial Interpolation Comparison 97," Journal of Geographic Information and Decision Analysis, vol. 2, no. 1-2, pp. 72-86, 1998.

[45] G. Q. Tabios and J. D. Salas, "A comparative analysis of techniques for spatial interpolation of precipitation1." 1985.

[46] C. H. Jarvis and N. Stuart, "A comparison among strategies for interpolating maximum and minimum daily air temperatures. Part II: The interaction between number of guiding variables and the type of interpolation method," Journal of Applied Meteorology, vol. 40, no. 6, pp. 1075-1084, 2001.DOI: $10.1175 / 15200450(2001) 040<1060$ :AC ASFI>2.0.CO;2 